\title{
Reconstruction of the Foundation of the Right to Request the Return of the Dowry
}

\author{
Huayue Zhang \\ Hangzhou Dianzi University Information Engineering School, Hangzhou 310000, China \\ E-mail: 1336995012@qq.com
}

\begin{abstract}
The "betrothal gift" system was born in the traditional culture of China for 5,000 years. After thousands of years of baptism, it still plays a huge role in China's wedding custom. With the development of modern society and economy, the amount of our betrothal benefit turned out to be higher, the more complicated and diverse the types of gifts are.The level of civilization in modern society has greatly improved, people are more advocating freedom, and the probability of divorce between men and women is getting higher and higher, so there are also many issues related to bride price disputes. Although my country has issued the "Interpretation of the Marriage Law (2)", which gives judges a legal basis for handling such cases, the judicial interpretation is too general and superficial, and cannot fully adapt to today's complex and changeable trial work. I will discuss my opinions and opinions from some of the current rules for the return of the lottery.
\end{abstract}

Keywords: Right to Return; Color Gift, Kind Customs

\section{Overview of bride price}

\subsection{The concept of dowry}

Regarding the word betrothal, my country's current laws and judicial interpretations have not yet made clear provisions on it. At present, there are two main explanations about the bride price, the theoretical circle and the folk interpretation. Theorists mainly believe that the bride price is a certain amount of money or property that the man or the man's family pays to the woman or the woman's family when the man and the woman enter the marriage contract or the marriage; The folks generally take the bride price as a sign of the conclusion of the marriage contract or the establishment of the marriage.

\subsection{The specific content of the gift return right in the law}

According to the Judicial Interpretation (2) of the Marriage Law: If the parties request the return of the bride price paid in accordance with the custom, if the following circumstances are found, the people's court shall support: (1) Both parties have not gone through the marriage registration formalities; (2) Both parties have gone through the marriage registration Those who do not live together through the formalities; (3) Payments before marriage have caused difficulties for the payer. The provisions of items (2) and (3) of the preceding paragraph shall be subject to divorce.

Our country's judicial interpretations are too general in terms of marriage return, and many complicated disputes over the return of the bride price cannot be resolved.

The basis for the right to return is different. If the property delivered by the lottery is not fulfilled due to the marriage contract or marriage, the donor has the right to request the recipient to return it, and the recipient loses the legal basis for legal possession of the gift, which constitutes a debt for improper gain. Therefore, the basis for the right to claim the $\underline{\text { return of the lottery For unjust enrichment. In general, after the gift is delivered, the recipient obtains the ownership of }}$ Copyright (C) 2020 Huayue Zhang

doi: 10.18282/le.v9i7.1475

This is an open-access article distributed under the terms of the Creative Commons Attribution Non-Commercial License

(http://creativecommons.org/licenses/by-nc/4.0/), which permits unrestricted non-commercial use, distribution, and reproduction in any medium, provided the original work is properly cited. 
the gift. If the cause cannot be determined, the donor has no right to revoke the gift and request the return of the gift. If there is a legal cause, the donor can follow the Contract Law "Relevant regulations request cancellation of the gift contract and return of the gift. Therefore, the basis of the general right to claim is the "Contract Law."

\section{Inadequacies of the gift return system}

\subsection{The scope of the dowry is blurred}

The term "betrothal gift" in China's marriage law only stipulates that Article 10 of the "Interpretation of the Marriage Law (2)" restricts the beauties to be paid according to the custom, but the specific scope of the beauties has not been clearly defined. This restriction is too general and vague. In folk customs, there are many kinds of names called beauties, including "three golds, car money, money for changing mouths, money for waists, money for holding pots, money for meeting, entanglement, money for clothes, water gifts, four-color gifts, and money tied up." The occurrence of folk customs is often closely related to people's living standards and environment. With the development of social modernization, many folk customs are changing with the times. This change in folk customs is also a major interference in the judge's decision on the determination and return of dowry. In modern society, men and women communicate with each other for the purpose of signing a marriage contract. During the relationship, the man or the woman often expresses affection to the other party through WeChat red envelopes and valuable gifts. How to calculate it? Is it returned as a gift or as a gift? Our country is a multi-ethnic country. Their wedding customs are different from place to place, from region to region, and from nation to ethnic group. The types of wedding gifts are so different that it is difficult to distinguish them. In the judicial interpretation, it is difficult to define "paid according to custom" in real life. It often results in different verdicts in similar cases, causes dissatisfaction among the people, hurts people's trust in the fairness of the law, and affects the stability of social order.

\subsection{There is no clear definition of "difficult life"}

In the rules for the return of the betrothal gift, the return requirement of "payment before marriage and causing difficulties for the payer" is mentioned. People who have different opinions about the word difficult in life have different opinions. Some people think that "difficulty in life" means that they cannot meet normal life needs. Some people think that the difficulty of life is a big gap with their original life.

One is relative and the other is absolute. How is this defined when the gift is returned? The payment of the dowry gift leads to a difficult life, and what is the law to assess. In real life, there are many factors that lead to difficulties in life. For example: after a period of time when Xiao Wang paid his girlfriend a gift, his father lost a lot of money because of playing cards, and once had a dispute with someone, he fell to the ground and caused a spinal injury. Large medical expenses. At this time, the relationship between Xiao Wang and his girlfriend broke up, and the marriage relationship was dissolved. Xiao Wang wanted to recover the wedding ceremony. He applied to the court for the return of the wedding ceremony on the grounds that the payment of the wedding ceremony caused difficulties in life. Whether the payment of the dowry caused difficulties in life, or the accident caused by the dispute between Xiao Wang's father and others, or the difficulty of life caused by Xiao Wang's father playing cards and losing money, it is difficult for the court to define. Subjective decisions are made.

\subsection{The identification of "common life" is not clearly defined}

First, the meaning is ambiguous. Regarding the meaning of "married couple living together", there is no clear stipulation on the common life once in law, and it is rarely explained in theory, but we can combine our understanding of the rights and obligations of both spouses in the "Marriage Law". Traditional concept to clarify its meaning.

First of all, husband and wife "co-living" means that after marriage, both men and women support each other, share the pressure of life, and create a sustainable and stable state of a better life. Subjectively, both men and women have the desire to live together for a long time; Objectively, both men and women can support each other, jointly fulfill the obligations of husband and wife and family, jointly bear the pressure and risks of life, and jointly create and enjoy a better life. The common life of husband and wife includes the following aspects:

(1) Common residence; 
(2) The common spiritual life of husband and wife mainly refers to the mutual understanding and comfort based on the identity of the spouse;

(3) The obligation of husband and wife to assist each other.

(4) Other family obligations shared by husband and wife.

Of these four, only the first common domicile can be checked by a judge, and the other three are abstract and easy to fabricate.

Second, the time of living together is not clear. Living together definitely refers to living together for a period of time, but how is this period of time defined? Is it months or more than a year? The judging standard is not clearly given in the law, and the lack of clear quantitative rules will bring difficulties to the judge when awarding the return of the gift. It will also bring disputes and injustices to both parties.

\subsection{The fault of both parties to the marriage contract was not included in the consideration of the return of the gift.}

In the current cases of the return of the gift, the judge often only makes the ruling based on some basic principles stipulated by the law, and does not consider the fault between the two parties received the gift. The ruling is unfair to the innocent party.

\section{Conclusions and recommendations}

\subsection{Clarify the scope of the gift}

I think the country should add a clear regulation on the bride price in the marriage law. Appropriately distinguish between different regions and different ethnic groups regarding the identification of the purpose of beauties. As well as some goods and money given to each other in the process of communication between men and women for the purpose of forming a marriage in modern society.

Modern society is a society with highly developed information. Many beauties and customs have undergone tremendous changes, some have been deleted, and new types of "beauties" in modern society have also been added, such as cars, artworks and other expensive things. These are not clearly stipulated in the current law as "gift gifts." I think that as long as the purpose of the marriage contract is for the purpose of giving large amounts of gifts between the parties, they should fall within the scope of the gift ceremony. If these specific scopes can be clarified in the legal interpretation, it will be of great help to the judge in ruling on the return of the "betrothal gift".

\subsection{Add identification description of "difficult life" and "common life"}

In the judicial interpretation, the law should clarify the specific scope of life difficulties, for example, the family assets within which are difficult, and there must be corresponding certification (family bank card balance, poor household certificate, etc.).In order to prevent someone from forging the condition of "family difficulties", the court should also find its neighbors for understanding when making a judgment.

Using quantitative methods to clarify these big concepts not only facilitates judges to make decisions, but also guarantees judicial justice. Increasing the identification of the meaning of the term "common life", how is it called common life? Only when the connotation is clear can we ensure fairness and justice in the ruling and increase the specific time frame for "common life". How long the parties to the marriage contract have not lived together should be determined at this point in time.

\subsection{Follow good customs}

In the case of the return of the bride price, I think it is necessary not only to consider some basic principles stipulated by the law, but also to consider whether the man and woman had any fault during the conclusion of the marriage contract. This reason is added to the consideration factors of the award return ruling. During the conclusion of the marriage contract, if the male and female parties had serious faults such as domestic violence, infidelity, and failure to fulfill their obligations, which led to the breakdown of the marriage contract, the judge returning the bride price should make a discretionary ruling based on the faults of both parties and follow good customs. Give legal protection to the weaker party in the marriage contract. Kindness and customs are our yearning for a better life. In the process of ruling, judges must 
not only make rulings strictly in accordance with the law, but also appropriately add some "emotions", extra-legal feelings, and follow good customs. This is not only considered when returning this "betrothal gift", but also applies to many other cases in our real life. Dharma is not only serious, it can also be "gentle".

\section{References}

1. Dongmei Xu: Jilin University, Research on the Legal Issues of Returning Gifts, 2015.

2. Yan Chenguang: "Judicial Interpretation of Marriage Law (2) Jurisprudence and Application", China Legal Publishing House, 2004 edition.

3. Huang Silk: "Inquiry into the basis and rules of "color gift" return" [J]. "Guild Forum". 2006, Issue 5.

4. Yang Suiquan et al.: "New Theory of Marriage and Family Law" [M]. Beijing. Law Press, 2003, first edition. 